\title{
Manfort, a blend from plant extracts used for infertility treatment and improvement of testicular histology
}

\author{
Mahmoud Elnahas Hussein* \\ Department of Embryo Bank and Genetic Resources Conservation, National Research Center, Dokki, Cairo, Egypt
}

Received: 13 November 2019

Accepted: 05 December 2019

\section{*Correspondence:}

Dr. Mahmoud Elnahas Hussein,

E-mail: elnahasinventor@gmail.com

Copyright: () the author(s), publisher and licensee Medip Academy. This is an open-access article distributed under the terms of the Creative Commons Attribution Non-Commercial License, which permits unrestricted non-commercial use, distribution, and reproduction in any medium, provided the original work is properly cited.

\begin{abstract}
Background: Flavonoids and polyphenols are groups of natural substances have variable phenolic configurations, many benefits as anti-inflammatory and anti-oxidants, and have many protective roles against male reproductive system disorders. Objective of this study was to study the safety as well as the efficacy of a blend from some plants extracts with precise ratios and rich with flavonoids and polyphenols named in this study as "Manfort" on the safety, fertility, and testicular histology in the male mice.

Methods: Firstly, some mice were used to evaluate the safety of Manfort and the levels of the testosterone in the serum of the treated animals with Manfort using biochemical analysis. Also, the efficacy of the Manfort on the histological architectures of the treated testis was evaluated using histological techniques.

Results: The mice treated with Manfort did not show any signs of mortality, toxicities and blood contents changes. Furthermore, testosterone levels in the serum elevated after administration with Manfort twice a day for 21 days compared with the non-treated mice. Additionally, the histological structures of the testis improved in the mice treated with Manfort compared with that in the non-treated animals.

Conclusions: In general flavonoids and polyphenols, which were found in the Manfort diet in a large amount, have important role in as antioxidant, anti-inflammatory and improve the fertility in the male mice. In the future these data might be very important to manufacture a drug composed from safe natural products for infertility and intractable diseases treatment.
\end{abstract}

Keywords: Flavonoids, Manfort, Polyphenols, Safety, Testosterone, Testis

\section{INTRODUCTION}

Recently, more than $15 \%$ of couples are infertile. There are many factors effecting the male fertility. For example, mainly male infertility is caused by low sperm numbers, abnormal sperm function or some disorders such as blockages that prevent the movement and delivery of sperm to reach the mature ova. Such diseases include, Illnesses, injuries, chronic health problems, lifestyle choices and other factors can play an important role to produce male infertility.
Natural product extracts especially plant natural products, can be used for treatment of many diseases, because of many reasons. Interestingly, plant natural products have no toxic effects or mortalities. In this regards, many studies reviled previously that flavonoids and polyphenols can improve testosterone metabolism and testicular tissue inflammation. ${ }^{1-3}$ Furthermore, low number of studies were performed for treatment of severe diseases using diets containing antioxidant flavonoid, induces glutathione and glutathione peroxidase activities for treatment of the inflammation produced in the testis. ${ }^{4}$ 
For example, Hesperetin is a cholesterol lowering flavonoid found in a number of citrus juices. Its flavonoid could prevent the testicular damage in mice, this performed by inhibition of oxidative stress, apoptosis, and inflammation mediators in addition to its upregulation of non-enzymatic antioxidants and endogenous enzymatic. ${ }^{5}$ Additionally, the total flavonoids of Epimedium extract strongly reduce the oxidative DNA damage in testis of rats via a p53-dependent pathway. ${ }^{6}$ Also, flavonoids of Cymbopogon citratus leaves extract reduces the activity and growth of PC-3 and HCT-116 carcinoma cell cultures. Moreover, the whole extract ameliorates testicular dysfunction and prevent the testicalr fail induced by anti-tumor drug such doxorubicin. $^{7}$

Total flavonoids in the containing taro flour (Colocasia esculenta) elevated the serum testosterone levels in the treated experimental animals. ${ }^{8}$ Also, Chrysin, which is a natural flavonoid, increase steroidogenesis by elevating the sensitivity of Leydig cells found in the interstitial area between the seminiferous tubules of the experimental animals. ${ }^{9}$ Furthermore, polyphenols which is found in the tea, has a very important protective effect against testicular torsion, which induced re-oxygenation injury in rats. $^{10}$

Testosterone has many important functions for the sexual intercourse or male fertilities. It is usually used in older men hypogonadism symptoms treatment, such as decreased mood decreased erectile dysfunction and decreased libido. ${ }^{11}$ Moreover, testosterone is anabolic steroid hormone that plays various physiological roles in the development of male reproductive system in utero and during puberty. Classically, testosterone is a hormone associated with attributes, behaviours, and roles associated with boys and men. Testosterone is used as a treatment for males with testosterone deficiency syndrome (TDS), a condition in men who experience symptoms produced by a decrease in serum testosterone. ${ }^{12-14}$ Flavonoids are food constituents that alter metabolic processes of the testosterone, and in this case it alters the process of the cyclooxygenase-2 pathway and causes the elevation in steroidogenic acute regulatory protein and, thus, elevates in testosterone levels in a natural way via flavonoids that can be found naturally in food. ${ }^{15,16}$

Here in this study, I invented a blend from effective plant extracts with precise ratios, by which the fertility parameters and the histological structure of the male testis improved. This drug got patent number (2017050673/2017-05-07) and named (Manfort). This study will provide some evidences about the safety as well as the effective role of Manfort on the male mice fertility including the following: Morphological and toxic signs were observed after the injection. The sperms morphology and activity were evaluated using light microscope and haemocytometer. Biochemical changes were studied using complete blood picture test.
Furthermore, testosterone hormone levels were investigated in treated and non- treated animals. The effective role of Manfort in male mouse fertility was tested using complete fertility analysis and histological tests. Although, further detailed studies are needed to clarify the role of the Manfort in the treatment of the fertility. The obtained data is the first and the novel study which describe the improvement of the fertility parameters such as testosterone levels and histological structure of the testicular tissue using the Manfort diet. The data obtained from this report revealed that of Manfort can help in the treatment of the infertility in males.

\section{METHODS}

\section{Materials}

Medical plants were collected from Sohag and El-wady El-Gadid governorates. Paraffin, xylene, ethyl alcohol, DPX, hematoxylin stain, and eosin stain were purchased from Sigma-Aldrich Chemical Co., UK.

\section{Manfort preparation and characterization}

\section{Manfort preparation}

The collected plants were dried and grinded separately to obtain its powder. Then these plants were mixed together with exact ratios with honeybee to make it similar to the paste. The prepared Manfort was used to the check the smell, color, and morphological appearance.

\section{Manfort chemical structure characterization}

Part of Manfort was used for chemical analysis using IR spectra to detect the main and reactive groups. The extract of was analyzed for the presence of alkaloids, saponins, tannins, glycoside, steroids, coumarins, carbohydrates, terpenoids and flavonoids, according to standard methods in $70 \%$ ethyl alcohol and water. Then, the extract was divided to three parts; the first one is dissolved in hexane, the second part is dissolved in ethyl acetate and the third part in aqueous solution. Later, phytochemical screening for these extracts was determined. Additionally, flavonoids and polyphenols were determined by standard chemical methods. Also, the activity of sample as antioxidant using DPPH free radical method was investigated.

\section{Animal eligibility criteria}

Adult male white mice (Mus musculus), 14 weeks old and $30 \mathrm{gm}$ in weight, were used for this study. All experiments are performed according to the guidelines for the care and use of animals approved by animal experiments committee in center of Embryo Bank and genetic resources conservation, national research centre. Animals were kept in cages in the animal house under the normal conditions of a 12:12-h light: dark cycle, $25^{\circ} \mathrm{C}$ 
room temperature and free access to water and food for two weeks before experimental time. The healthy animals with the same weight $(30 \mathrm{gm})$, and with no symptoms of illness or inflammation were included for this experiment. But the animals with lower or higher weight and with symptoms of illness were excluded from this experiment.

\section{Methods and experimental animals}

Thirty-two mice were divided into 2 groups. The first group contained 16 mice was left without any treatment and considered as control. The second group contained 16 mice, and was administrated orally with $75 \mathrm{mg} / \mathrm{mice}$, twice a day, for 21 days consequently with disposable mouse gavage.

\section{Safety of Manfort}

A total of 5 mice from control as well as treated animals with Manfort were used for monitoring the toxic signal or mortalities during the experimental time.

\section{Biochemical analysis}

To check the biochemical analysis of blood contents, blood was drained from 5 mice from control and treated mice with Manfort. The target biochemical analysis were complete blood picture with differential count of the white blood cells, and total testosterone hormone in the serum. To check the complete blood picture blood was drained from 3 mice from control and treated groups in Lavender-Top Tube -EDTA to prevent blood coagulation and kept in the $4^{\circ} \mathrm{C}$. For the testosterone hormone level in the serum, blood was drained from 3 mice from control and treated groups in Lavender-Top Tube without EDTA and kept for 1 hour at room temperature. After blood coagulation, the blood serum was collected by centrifugation of the blood by centrifuge (14000 rpm/10 $\min )$. Then blood serum were kept in the $-20^{\circ} \mathrm{C}$ for testosterone hormone analysis using.

\section{Semem analysis test}

To make this analysis, $10 \mu \mathrm{l}$ of semen was collected from 3 mice from both control and treated animals treated with Manfort using micropipette from the seminal vesicle. Some of the semen were analyzed for the activity and movement of the sperms. Other semen was used for the sperm count using hemocytometer.

\section{Efficacy of Manfort on the testis histology}

The testes of 3 mice from control and treated mice with Manfort was collected and kept in Carnoy solution (absolute ethanol $(60 \mathrm{ml})$, chloroform $(30 \mathrm{ml})$, glacial acetic acid $(10 \mathrm{ml})$ for 1 hour or Bouin's solution (saturated aqueous picric acid $(75 \mathrm{ml})$, formalin $(25 \mathrm{ml})$ and glacial acetic acid $(5 \mathrm{ml})$ for 24 hours. Then the samples were washed and dehydrated in ascending series of alcohol $(50 \%, 70 \%, 90 \%, 100 \%$ and $100 \%)$, cleared in methyl benzoat for 24 hours, incubated in toluene for 30 mins. To prepare paraffin sections, testis tissues were infiltrated in the paraffin and kept for 6 hours in the oven under $59^{\circ} \mathrm{C}$. For light microscope imaging, paraffin sections $(7 \mu \mathrm{m})$ of non-treated and treated testis was sectioned from the paraffin blocks and affixed to glass slides. Sections then were deparaffinized in xylene and hydrated through descending concentrations of ethanol $(100 \%, 100 \%, 90 \%, 70 \%$ and $50 \%)$ and washed in distilled water. Then sections were stained with hematoxylin and eosin stains, dehydrated again in ascending concentrations of ethanol $(50 \%, 70 \%, 90 \%$, $100 \%$ and $100 \%$ ), mounted in DPX, and observed under (Axio Scope.A1, Carl ZEISS, Germany) equipped with AxioCamERc5s camera.

\section{RESULTS}

\section{Manfort preparation and characterization}

\section{Morphological characterization}

The Manfort is a blend from grinded herbs and mixed with honeybee to form a blend like a paste. This blend is easy to eat and characterized with brown color and acceptable smell.

\section{Chemical analysis}

Based on the IR spectrum analysis Manfort composed chemically from flavonoids, carbohydrates, coumarins, steroids, terpenoids, glycosides and polyphenols. The phytochemical screening showing that Manfort has higher ratio from carbohydrates, flavonoids, and polyphenols. The exact percentage of some targeted chemicals was determined by the standard chemical method, and the concentration of flavonoids was 1.98 $\mathrm{mg} / \mathrm{gm}$ and polyphenols was $3.43 \mathrm{mg} / \mathrm{gm}$ (Table 1). Additionally, the antioxidant activity of the Manfort blend calculated using 2, 2-diphenyl-1-picrylhydrazyl (DPPH) method. The inhibition percentage of Manfort increased by increasing the concentration. For example, the inhibition percentage of Manfort at concentration 7.25 $\mathrm{mg} / \mathrm{ml}$ was about $42 \%$. The activity of the Manfort as antioxidant showed that, the IC50 was calculated and found to be $8.93 \mathrm{mg} / \mathrm{ml}$ compared with standard antioxidant ascorbic acid $(0.3 \mathrm{mg} / \mathrm{ml})$ (Table 2).

\section{Safety of Manfort}

After administration the mice with a dose of $75 \mathrm{mg} / \mathrm{mice}$ twice a day for 21 days of Manfort, it was observed that, there was no toxic signs or symptoms and no mortalities in the treated mice. The administrated mice with Manfort were actively living during all the experiment time. The appetite of the treated mice with Manfort was stable during the experimental time (data is not shown). The blood parameters analysis showed that, there was not significant change in the blood contents between treated 
and non-treated animals. The WBCs in the non-treated mice was $3.9 \times 103$ and it was $3.8 \times 103$ for the Manfort treated mice. Furthermore, RBCs, platelets, lymphocytes and monocytes didn't change after administration of the Manfort compared with the non-treated animals.
However, there was no signal for the toxicity of Manfort, fortunately increased the hemoglobin in the administrated group with Manfort $(12.5 \mathrm{~g} / \mathrm{dl})$ slightly increased as compared with the control (11.8 g/dl) (Table 3).

Table 1: The preliminary phytochemical screening of Manfort.

\begin{tabular}{|c|c|c|c|c|}
\hline Components & Hexane extract & Aqueous extract & Ethyl acetate extract & Ethyl alcohol $70 \%(v / v)$ \\
\hline Flavonoids & - & ++ & ++ & - \\
\hline Carbohydrates & - & +++ & - & - \\
\hline Coumarins & - & - & ++ & - \\
\hline Steroids & ++ & - & - & - \\
\hline Tannins & - & - & - & + \\
\hline Terpenoids & ++ & - & - & - \\
\hline Glycosides & - & ++ & - & - \\
\hline Polyphenols & - & - & - & ++ \\
\hline
\end{tabular}

+++: Strong intensity reaction, ++ : Medium intensity reaction, + : Weak intensity reaction, - : Non detected.

Table 2: The activity of Manfort as antioxidant using 2,2-diphenyl-1-picrylhydrazyl (DPPH) free radical method.

\begin{tabular}{|ll|}
\hline Concentration $\mathrm{mg} / \mathrm{ml}$ & Inhibition percentage \\
\hline 1.81 & 15.68 \\
\hline 3.62 & 23.07 \\
\hline 7.25 & 41.96 \\
\hline
\end{tabular}

\section{Morphometric analysis}

The body weight of the mice administrated with Manfort slightly increased by $18 \%$ compared with the non-treated mice (Figure 1A). Additionally, the testis weight increased in the treated mice with Manfort with $19 \%$ compared with the non-treated mice (Figure 1B).

\section{Sperms morphology and activity}

The investigation of sperms movement and activity under the microscope, the sperms morphology, activity and mobility improved in the mice administrated with 75 $\mathrm{mg} / \mathrm{mouse}$ dose (twice a day for 21 days) compared with the non-administrated mice.

\section{Sperms number}

Using the histological finding, the investigation under the light microscope and from the hemocytmeter data, the number of sperms increased by $47 \%$ in the mice administrated with $75 \mathrm{mg} / \mathrm{mouse}$ dose (twice a day for 21 days) compared with the non-administrated mice (Figure 1C).

\section{Testosterone hormone}

The total testosterone hormone levels increased by $12 \%$ in the mice administrated with $75 \mathrm{mg} / \mathrm{mouse}$ dose (twice a day for 21 days) compared with the non-administrated mice (Figure 1D).

Fertility increase and histological improvement of the testis

Figure 1, 2 and 3 shows, administration of Manfort to mice for 21 days consequently showed many positive signs for Manfort efficacy on the fertility such as, sperm counts and sperm activity, testosterone levels and testis histology improvement.

Table 3: The mean values of the mice blood contents for control and Manfort administrated mice $(n=3)$.

\begin{tabular}{|lllllll|}
\hline Group & RBCs & WBCs & Hemoglobin & Platelets & Lymphocytes & Monocytes \\
\hline Control & $5.3 \times 10^{3}$ & $3.9 \times 10^{3}$ & $11.8 \mathrm{~g} / \mathrm{dl}$ & $243 \times 10^{9}$ & $2.7 \times 10^{3}$ & $0.7 \times 10^{3}$ \\
\hline Manfort & $5.8 \times 10^{3}$ & $3.8 \times 10^{3}$ & $12.5 \mathrm{~g} / \mathrm{dl}$ & $241 \times 10^{9}$ & $2.6 \times 10^{3}$ & $0.7 \times 10^{3}$ \\
\hline
\end{tabular}

In general, histologically, testis is subdivided into hundreds of coiled tubules known as seminiferous tubules. Internally, the tubules are lined with seminiferous epithelium, which consists of spermatogenic cells and Sertoli cells. Spermatogenic cells contains several cell types such as spermatogonia, primary 
spermatocytes, secondary spermatocytes, spermatids, spermatozoa. Interstitial tissue between the seminiferous tubules is continuous with a layer of loose connective tissue containing several types of cells such as Leydig cells and macrophages. Leydig cells occur in clusters and characterized with strongly eosinophilic and finely granular cytoplasm. Also, the nucleus of the Leydig cells is large, round and often located eccentric in the cell.

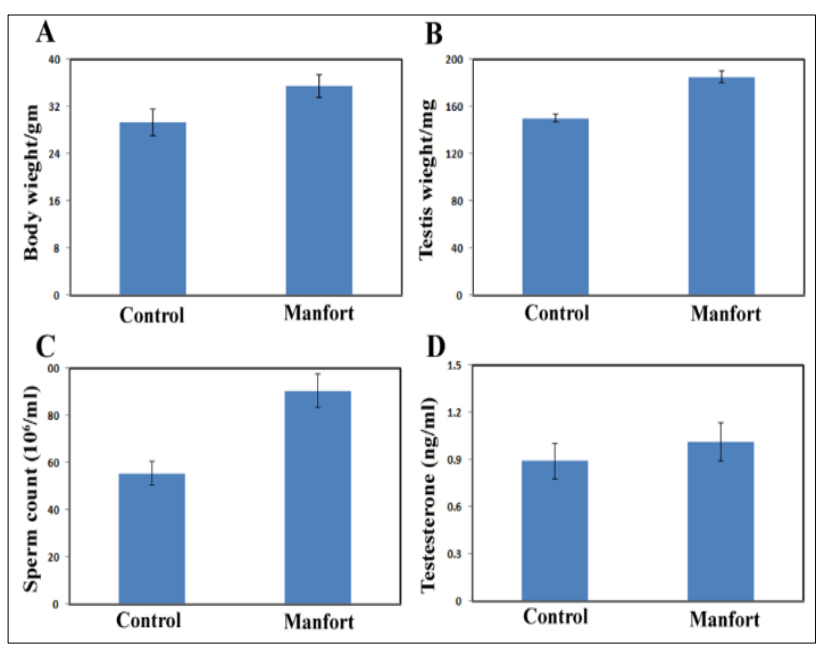

Figure 1: (A) the body weight of treated mice with Manfort and non-treated mice (control), (B) the testis weight of treated mice with Manfort and non-treated mice, (C) the sperm counts of treated mice with Manfort and non-treated mice and (D) the serum testosterone levels in treated mice with Manfort and non-treated mice. $\mathrm{SD}=3$ mice.

The histological findings showed many positive findings after administration with the Manfort. For example, the wall and epithelium of the epididymal vesicles were well developed and intact after treated with Manfort compared with the wall of the control epididymis. Additionally, the number of the sperms in the epididymis of mice treated with Manfort increased as compared with the non-treated mice epididymis (Figure 2).
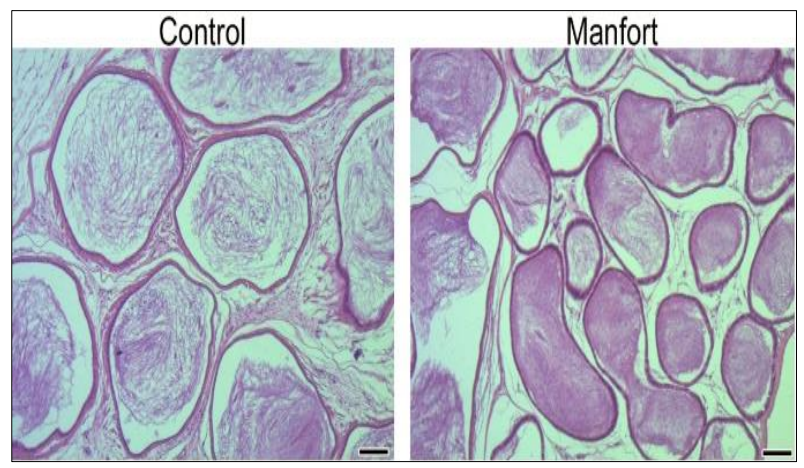

Figure 2: Light microscope images of epididymis of control mice showed low number of sperms and epididymis of administrated mice with Manfort showed higher number of sperms. Scale bar $=10 \mu \mathrm{m}$.
Additionally, the histological structure of the testis in the mice administrated with Manfort improved in many regions of the testis and became more intact and adhered each other's compared with the non-administrated mice. For example, the seprmetogonia cells and the interstitial area cells becomes more intact and denser with many Leydig cells and immune cells as compared with control. The number of sperms produced by the spermatogonia in the seminiferous tubules increased as compared with control. Additionally, the spermatogonia cells improved and became more intact as compared with control (Figure 3).
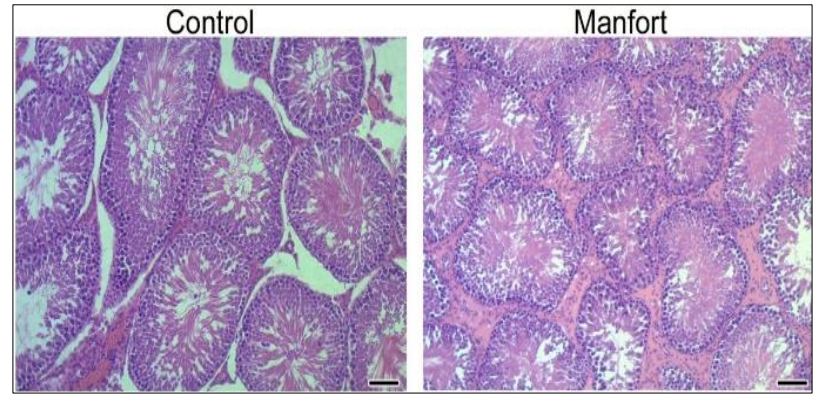

Figure 3: Light microscope images of testis of control mice with non-intact seminiferous tubules, and nonintact interstitial area cells and testis of administrated mice with Manfort showed intact seminiferous tubules and interstitial area cells. Scale bar $=\mathbf{1 0} \mu \mathrm{m}$.

\section{DISCUSSION}

In this report the concentration of the flavonoids and polyphenols in the Manfort blend is higher than other components. Additionally, the previous studies showed that the flavonoids and polyphonoles included in the ingested diets have protective role, antioxidants effects and anti-inflammatory properties. ${ }^{1-3}$ Therefore I will discuss the data in this report based on the properties of flavonoids and polyphonoles. Flavonoids, including isoflavones, are natural extracts mainly found in our food. These natural components are used as alternative medicine. Additionally, they are increasingly being ingested by the many population. There are many beneficial properties have been attributed to flavonoids dietary compounds. These properties include antiinflammatory, anti-oxidant, and anti-carcinogenic effects. ${ }^{17,18}$ Manfort in this study contains $1.98 \mathrm{mg} / \mathrm{gm}$ of flavonoids. Therefore, Manfort in this study can improve the histology of the testis and increase the sperm number through the beneficial properties of the flavonoids in the administrated diet. Manfort contains many reactive groups came from the different types of plant extracts. For example, Manfort contains $3.43 \mathrm{mg} / \mathrm{gm}$ from polyphenols, which additionally can improve the histology and increase the testosterone levels in the serum. Previously, total flavonoids of Epimedium is the main active composition of Epimedium which is truly important to treat male reproductive problems. Also, Epimedium exerted extremely protective effects on the structural and functional injury of male mice reproductive 
system and reduced apoptosis in spermatogenic cells by blocking cyclophosphamide-induced oxidative stress. ${ }^{19}$ Many studies reviled previously that there was a relationship between flavonoids in the ary components and testosterone metabolism. ${ }^{1,2}$ Furthermore, diet including containing polyphenols, can protect testicular tissue from damage and improve the histological structure of the testis tissue. ${ }^{3}$ Testosterone is a pleiotropic hormone that plays various physiological roles in the development of male genitalia in utero and during puberty. ${ }^{17}$ The amount of the flavonoids in the Manfort might regulate the level of the testosterone level in the serum after oral administration of $75 \mathrm{mg} / \mathrm{mouse}$ for 21 consecutive days. The increase in the level of the testosterone can promote the sperm production and keep the function of the spermatogenic cells.

\section{CONCLUSION}

The previous studies about the beneficiary of the natural products extracts such as flavonoids and polyphenols to improve the function of the reproductive systems in the males are in consistent with our data about the efficacy of Manfort for the infertility treatment. Therefore, Manfort can improve fertility of male mice and it can be used for infertility therapeutics after further investigations.

Funding: No funding sources

Conflict of interest: None declared

Ethical approval: The study was approved by the Institutional Ethics Committee

\section{REFERENCES}

1. Jenkinson C, Petroczi A, Naughton DP. Effects of ary Components on Testosterone Metabolism via UDPGlucuronosyltransferase. Front Endocrinol (Lausanne). 2013;4:80.

2. Dai R, Jacobson KA, Robinson RC, Friedman FK. Differential effects of flavonoids on testosteronemetabolizing cytochrome P450s. Life Sci. 1997;61(7):PL75-80.

3. Budin SB, Abdul Rahman WZ, Jubaidi FF Yusof NLM, Taib IS, Zainalabidin S. Roselle (Hibiscus sabdiriffa) polyphenol-rich extract prevents testicular damage of diabetic mice. J Appl Pharma Sci. 2018;8(2):065-70.

4. Abarikwu SO, Olufemi PD, Lawrence CJ, Wekere FC, Ochulor AC, Barikuma AM. Rutin, an antioxidant flavonoid, induces glutathione and glutathione peroxidase activities to protect against ethanol effects in cadmium-induced oxidative stress in the testis of adult rats. Androl. 2017;49(7):e12696.

5. Samie A, Sedaghat R, Baluchnejadmojarad T, Roghani M. Hesperetin, a citrus flavonoid, attenuates testicular damage in diabetic rats via inhibition of oxidative stress, inflammation, and apoptosis. Life Sci. 2018;1(210):132-9.

6. Zhao H, Song L, Huang W, Liu J, Yuan D, Wang Y, et al. Total flavonoids of Epimedium reduce ageingrelated oxidative DNA damage in testis of rats via p53dependent pathway. Androl. 2017;49(10):1-3.

7. Ahmed NZ, Ibrahim SR, Ahmed-Farid OA. Quercetin and Apigenin of Cymbopogon citratus mediate inhibition of HCT-116 and PC-3 cell cycle progression and ameliorate Doxorubicin-induced testicular dysfunction in male rats. Biomed Res Ther. 2018;5(7):2466-79.

8. Ribeiro GG, Pessôa LR, de Abreu MD, Corrêa LB, Pereira AA, Chagas MA, et al. Taro flour (Colocasia esculenta) increases testosterone levels and gametogenic epithelium of Wistar rats. Journal of developmental origins of health and disease. 2018;9(4):373-6.

9. Jana K, Yin X, Schiffer RB, Chen JJ, Pandey AK, Stocco DM, et al. Chrysin, a natural flavonoid enhances steroidogenesis and steroidogenic acute regulatory protein gene expression in mouse Leydig cells. J Endocrinol. 2008;197(2):315-23.

10. He QX, Zhang YG, Hu X, Guo YT. Tea polyphenols protects the testis following testicular torsion/detorsion in rats. Zhonghua Nan Ke Xue. 2010;16(7):615-8.

11. Patel AS, Leong JY, Ramos L, Ramasamy R. Testosterone is a contraceptive and should not be used in men who desire fertility. World J Mens Health. 2019;37(1):45-54.

12. Walker WH. Non-classical actions of testosterone and spermatogenesis. Philos Trans R Soc Lond B Biol Sci. 2010;365:1557-69.

13. Smith LB, Walker WH. The regulation of spermatogenesis by androgens. Semin Cell Dev Biol. 2014;30:2-13.

14. Walker WH, Cheng J. FSH and testosterone signaling in Sertoli cells. Repro. 2005;130:15-28.

15. Beecher GR. Overview of dietary flavonoids: nomenclature, occurrence and intake. $J$ Nutr. 2003; $133: 3248$ S-3254S.

16. Rojas DP, Pandey AK. Natural Compounds to Counteract Testosterone Depletion in Aging. J Steroids Horm Sci. 2014;5:e112.

17. Patel AS, Leong JY, Ramos L, Ramasamy R. Testosterone is a contraceptive and should not be used in men who desire fertility. World J Men's Health. 2019;37(1):45-54.

18. Galati G, O'Brien PJ. Potential toxicity of flavonoids and other dietary phenolics: significance for their chemopreventive and anticancer properties. Free Radic Biol Med. 2004;37(3):287-303.

19. Yuan D, Wang H, He H, Jia L, He Y, Wang T, et al. Protective effects of total flavonoids from Epimedium on the male mouse reproductive system against cyclophosphamide-induced oxidative injury by upregulating the expressions of SOD3 and GPX1. Phytother Res. 2014;28(1):88-97.

Cite this article as: Hussein ME. Manfort, a blend from plant extracts used for infertility treatment and improvement of testicular histology. Int J Reprod Contracept Obstet Gynecol 2020;9:352-7. 